\title{
Thos. L. Casey's Revision of the Stenini of America North of Mexico,
}

\author{
besprochen von
}

Dr. G. Kraatz.

Wir glaubten durch Erichson's Genera et Species Staphylinorum eine ungefähre Idee von der Zahl der exotischen Arten vieler Staphylinen-Gattungen zu haben, namentlich auch von der der nord- und südamerikanischen, von denen die Herren Zimmermann und Moritz ziemlich viele gesammelt hatten. Dafs die Zahl der exotischen Arten indessen eine ungeahnt grofse, zeigt uns Casey's Revision sehr deutlich. Der fleifsige Autor beschreibt auf 206 enggedruckten Seiten grofs Octav 174 Stenini, von denen drei auf die Gattung Dianous, 130 auf Stenus, 41 auf Areus kommen; davon sind ihm nur 4 Stenus und ein Areus unbekannt geblieben. Diese Gattung umfafst die Arten mit deutlich gelapptem vierten Fufsgliede, unter welchen sich übrigens nur vier mit gerandetem Hinterleibe befinden. Von den Stenen mit einfachem viertem Glied (Fufsgliede) wird die Untergattung Muticus mit zwei Arten abgezweigt, deren Fühlerglieder nach der Spitze zu deutlich verbreitert sind. Unter den 130 echten Stenus - Arten sind etwa 20 früher beschrieben, von denen vier dem Autor indessen ganz unbekannt geblieben sind, also sind $110 \mathrm{neu}$. Von den Areus-Arten waren fünf durch Erichson beschrieben, also 36 neu. Eine Anzahl Arten sind von Crotch, Fauvel und Schwarz in litteris benannt. Dieser letztere ist ein Deutscher (Schlesier), der in Berlin studirte und dann nach Amerika auswanderte, wo er sehr fleifsig gesammelt hat. Leider hat er mit seiner Heimath wenig Verbindungen unterhalten.

Von den beschriebenen Arten sind 32 der Atlantic Region eigenthümlich, 33 der Lake Region, 50 der Pacific Region, 24 den beiden ersteren gemeinsam, keine den beiden letzteren, fünf allen drei. Die Beschreibungen sind sehr ausführlich, leider nur in englischer Sprache gegeben, die Geschlechtsunterschiede am Abdomen, wo ein oder beide Geschlechter bekannt waren, hervorgehoben. Der Verfasser hat einige Ex. seiner werthvollen Arbeit zur Vertheilung an Mitglieder des Vereins gesendet, wofür ich ihm in deren Namen hier herzlichen Dank sage. 


\section{$2 \mathrm{BHL}$ Biodiversity Heritage Library}

Kraatz, G. 1885. "Thos. L. Casey's Revision of the Stenini of America North of Mexico." Deutsche entomologische Zeitschrift 1885(1), 148-148. https://doi.org/10.1002/mmnd.48018850115.

View This Item Online: https://www.biodiversitylibrary.org/item/103411 DOI: https://doi.org/10.1002/mmnd.48018850115

Permalink: https://www.biodiversitylibrary.org/partpdf/235334

\section{Holding Institution}

Harvard University, Museum of Comparative Zoology, Ernst Mayr Library

\section{Sponsored by}

Harvard University, Museum of Comparative Zoology, Ernst Mayr Library

\section{Copyright \& Reuse}

Copyright Status: Public domain. The BHL considers that this work is no longer under copyright protection.

This document was created from content at the Biodiversity Heritage Library, the world's largest open access digital library for biodiversity literature and archives. Visit BHL at https://www.biodiversitylibrary.org. 